\title{
Stochastic Modeling to Determine the Economic Effects of Blanket, Selective, and No Dry Cow Therapy
}

\author{
K. Huijps ${ }^{\star 1}$ and $H$. Hogeveen ${ }^{\star} \dagger$ \\ ${ }^{*}$ Business Economics, Wageningen University, the Netherlands \\ †Faculty Veterinary Medicine, Utrecht University, the Netherlands
}

\begin{abstract}
In many countries, blanket dry cow therapy (DCT) is the standard way to dry off cows. Because of concerns about antibiotic resistance, selective DCT is proposed as an alternative. The economic consequences of different types of DCT were studied previously, but variation between input traits and different types of pathogens were not taken into account. The goal of this study was to create a stochastic Monte Carlo model to simulate the dynamics of intramammary infections (IMI) around the dry period to predict the economic consequences of DCT for different types of pathogens (Streptococcus agalactiae, Streptococcus dysgalactiae, Streptococcus uberis, Staphylococcus aureus, and Escherichia coli). The traits used in the model can be varied. The probabilities within the basic situation were collected from the literature and, because not all information needed was available in the literature, by interviewing experts $(\mathrm{n}=$ 10). The expert opinions were translated into minimum, most expected, and maximum values for each of the different probabilities. For Dutch farmers, the costs associated with mastitis and mastitis control around the dry period varied between $€ 10.61$ and $€ 26.61$ (average $€ 15.60)$ for blanket DCT, between $€ 4.86$ and $€ 29.41$ (average $€ 13.72$ ) for selective DCT, and between $€ 4.08$ and $€ 42.60$ (average $€ 18.02$ ) for no DCT. Although there were small differences between the treatment groups, the variation within the treatment groups was much larger. The major portion of the costs for selective treatment (59\% of the total costs) and no DCT (82\%) was derived from the costs of clinical mastitis after calving, and for blanket DCT, the costs of treatment (65\%) exceeded the costs of clinical mastitis (27\%). The cost of mastitis around the dry period was most sensitive to a change in the risk of new IMI during the dry period, spontaneous cure, and costs associated with the antibiotic treatment. The optimal decision to dry off cows depends on the attitude of the farmer toward risk and
\end{abstract}

Received June 15, 2006.

Accepted October 12, 2006.

${ }^{1}$ Corresponding author: k.huijps@vet.uu.nl other farm-specific traits and probabilities such as the new IMI rate during the dry period. Therefore, it is necessary to make farm-specific calculations so that farmers are able to factor this information into their decisions when choosing the best DCT for their situations.

Key words: dry cow therapy, economics, stochastic, mastitis

\section{INTRODUCTION}

Blanket dry cow therapy (DCT) with antibiotics is one of the points recommended in the "5 Points Mastitis Control Plan" since the 1970s to control the risk of IMI after drying off (Dodd et al., 1969). As in many other countries, most farmers in the Netherlands follow this advice and use blanket DCT for mastitis control. Antibiotic DCT has 2 important functions: to eliminate IMI present at drying off and to prevent new IMI during the nonlactating period (Bradley and Green, 2001). Other studies have shown that cows treated at drying off had less clinical mastitis compared with untreated cows (Schukken et al., 1993; Bradley and Green, 2000).

Because of antibiotic resistance and public opinion, a selective use of antibiotics is required, because not every cow has an infection at drying off nor does every cow become infected during this period. Thus, numerous cows are treated unnecessarily. Selective DCT has been proposed as an alternative to avoid unnecessary antibiotic use (Østerås et al., 1991) and this has produced positive results (Berry and Hillerton, 2002b; Robert et al., 2006). However, its economic consequences are unreported, as are the dynamics of IMI around the dry period-both of which are necessary when advising farmers about optimal manners of treatment.

Costs of mastitis around the dry period (CMDP) depend on production losses and the value of these losses, culling, and veterinary, antibiotic, discarded milk, and labor costs. These costs were partly estimated for lactation (Houben et al., 1993; Østerås, 2000) and partly for the dry period. They were partly estimated by McNab and Meek (1991) who reported that it was economically beneficial to use blanket DCT instead of no DCT in Canada; however, there was much variation in their 
results, and selective DCT was not included in the research. Other factors have been ignored or incorrectly estimated in previous studies. For example, most research with DCT strategies is not pathogen-specific and is at the cow level instead of the herd level. These 2 aspects are important to include because each pathogen has its own characteristics and because farm decisions are mostly made at the herd level.

Because the stochastic Monte Carlo method seems the optimal way to consider the variation, the goal of this study was to develop a farm-level, stochastic Monte Carlo model to simulate the dynamics and economics of IMI around the dry period. This model was then used to evaluate the economic effect of 3 treatment strategies (blanket DCT, selective DCT, and no DCT) for Dutch conditions, taking into account variation in variables and probabilities and pathogen-specific values.

\section{MATERIALS AND METHODS}

\section{Model Description}

Monte Carlo simulation is a computer technique to simulate the reaction of a model under repeated samples. The model is created in @Risk (Palisade Corporation, Ithaca, NY). A farm-level stochastic Monte Carlo simulation model was built with a multiple process structure to calculate CMDP, in which model outcomes are generated in 3 steps. First, the model simulates the dynamics of infection for each animal; second, it calculates the economic effects for each animal; and finally, it aggregates the different results to calculate herd-level outcomes. The first and second steps are represented in Figure 1.

All discrete events and variability at the cow level are triggered stochastically using random numbers drawn from relevant distributions. With this technique, variability of parameters can be specified, so model behavior can be controlled by a set of decision variables that describe the farm characteristics.

Dynamics of Infection. The model is capable of simulating the dynamics of IMI around the dry period of individual cows. It focuses on infections with Streptococcus uberis (SUB), Streptococcus dysgalactiae (SDY), Streptococcus agalactiae (SAG), Staphylococcus aureus (SAU), and Escherichia coli (ECO). It is assumed that a cow can have only one infection at a time. A number of consecutive simulation steps are taken per cow (Figure 1). A description of the model is given below.

At first, each cow (i) has the attribute milk production (MP), which is normally distributed (N), with an average milk production of the herd $\left(\mu_{\mathrm{mp}}\right)$ and an average variation of this production $\left(\sigma_{\mathrm{mp}}\right)$ :

$$
\mathrm{MP}_{\mathrm{i}}=\mathrm{N}\left(\mu_{\mathrm{mp}}, \sigma_{\mathrm{mp}}\right)
$$

In the next step, the infection status at drying off of each cow (IMIdo $_{\mathbf{i}}$ ) is determined. Possible values of IMIdo are uninfected (NEG) or infected with one of the following pathogens: SAG, SUB, SDY, SAU, or ECO. Every pathogen has its own probability of occurrence:

$$
\begin{aligned}
& \text { IMIdo }_{\mathrm{i}}=\operatorname{discrete}[(\mathrm{NEG}, \mathrm{SAG}, \mathrm{SUB}, \mathrm{SDY}, \mathrm{SAU}, \mathrm{ECO}) ; \\
& \left.\quad\left(\mathrm{P}_{\mathrm{NEG}, \mathrm{do}}, \mathrm{P}_{\mathrm{SAG}, \mathrm{do}}, \mathrm{P}_{\mathrm{SUB}, \mathrm{do}}, \mathrm{P}_{\mathrm{SDY}, \mathrm{do}}, \mathrm{P}_{\mathrm{SAU}, \mathrm{do}}, \mathrm{P}_{\mathrm{ECO}, \mathrm{do}}\right)\right] .
\end{aligned}
$$

Every cow (i) has a probability of being treated $\left(\mathrm{PT}_{\mathrm{i}}\right)$ for which $\mathrm{PT}_{\mathrm{i}}$ has the values 1 (treated) or 0 (not treated). The PT is dependent on the treatment (T) strategy (blanket, selective, or no DCT). With blanket DCT, every cow is treated; with no DCT, no cow is treated; and with selective DCT, the probability of being treated is dependent on the selection sensitivity and specificity.

$$
\mathrm{T}_{\mathrm{i}}=\operatorname{discrete}\left[(1,0),\left(\mathrm{PT}_{\mathrm{i}}, 1-\mathrm{PT}_{\mathrm{i}}\right)\right] .
$$

Cow (i) can be cured $\left(\mathrm{C}_{\mathrm{i}}\right)$ because of treatment or because spontaneous cure can occur. These probabilities are different for the different pathogens. The value $\mathrm{C}_{\mathrm{i}}$ can be 0 (cured) or 1 (not cured). When a cow is cured or when there was no infection, it has a chance of being reinfected with a new (or the same) pathogen during the dry period $\left(\mathbf{I M I d p}_{\mathbf{i}}\right)$; IMIdp $_{\mathrm{i}}$ can have the same values as IMIdo ${ }_{\mathrm{i}}$ :

$$
\begin{gathered}
\text { IMIdp }_{\mathrm{i}}=\mathrm{IMIdo}_{\mathrm{i}} \times \mathrm{C}_{\mathrm{i}} \\
+\operatorname{discrete}[(\mathrm{NEG}, \mathrm{SAG}, \mathrm{SUB}, \mathrm{SDY}, \mathrm{SAU}, \mathrm{ECO}) \\
\left.\left(\mathrm{P}_{\mathrm{NEG}, \mathrm{dp}}, \mathrm{P}_{\mathrm{SAG}, \mathrm{dp}}, \mathrm{P}_{\mathrm{SUB}, \mathrm{dp}}, \mathrm{P}_{\mathrm{SDY}, \mathrm{dp}}, \mathrm{P}_{\mathrm{SAU}, \mathrm{dp}}, \mathrm{P}_{\mathrm{ECO}, \mathrm{dp}}\right)\right] \\
\times 1-\mathrm{C}_{\mathrm{i}} .
\end{gathered}
$$

The IMIdp $\mathrm{p}_{\mathrm{i}}$ can become an infection at calving (IM$\left.\mathbf{I c}_{\mathrm{i}}\right)$; IMIc $\mathrm{c}_{\mathrm{i}}$ can have the same values as IMIdo $_{i}$ and

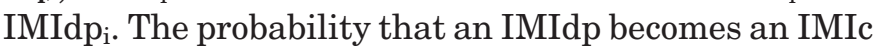
is dependent on the pathogen involved:

$$
\begin{aligned}
& \text { If IMIdp } \mathrm{i}_{\mathrm{i}} \neq \mathrm{NEG}_{\mathrm{N}} \text { then IMIc } \mathrm{I}_{\mathrm{i}}=\mathrm{IMIdp}_{\mathrm{i}} \times \mathrm{C}_{\mathrm{i}}+\text { discrete } \\
& {[(\mathrm{NEG}, \mathrm{SAG}, \mathrm{SUB}, \mathrm{SDY}, \mathrm{SAU}, \mathrm{ECO}) ;} \\
& \left.\left(\mathrm{P}_{\mathrm{NEG}, \mathrm{c}}, \mathrm{P}_{\mathrm{SAG}, \mathrm{c}}, \mathrm{P}_{\mathrm{SUB}, \mathrm{c}}, \mathrm{P}_{\mathrm{SDY}, \mathrm{c}}, \mathrm{P}_{\mathrm{SAU}, \mathrm{c}}, \mathrm{P}_{\mathrm{ECO}, \mathrm{c}}\right)\right] \\
& \times 1-\mathrm{C}_{\mathrm{i}} \text { else IMIc } \mathrm{I}_{\mathrm{i}}= \\
& \text { discrete }[(\mathrm{NEG}, \mathrm{SAG}, \mathrm{SUB}, \mathrm{SDY}, \mathrm{SAU}, \mathrm{ECO}) ; \\
& \left.\left(\mathrm{P}_{\mathrm{NEG}, \mathrm{c}}, \mathrm{P}_{\mathrm{SAG}, \mathrm{c}}, \mathrm{P}_{\mathrm{SUB}, \mathrm{c}}, \mathrm{P}_{\mathrm{SDY}, \mathrm{c}}, \mathrm{P}_{\mathrm{SAU}, \mathrm{c}}, \mathrm{P}_{\mathrm{ECO}, \mathrm{c}}\right)\right]
\end{aligned}
$$

Finally, the probability of a case of clinical mastitis in the next lactation $\left(\mathrm{CM}_{\mathrm{i}}\right)$ is calculated. The value of 


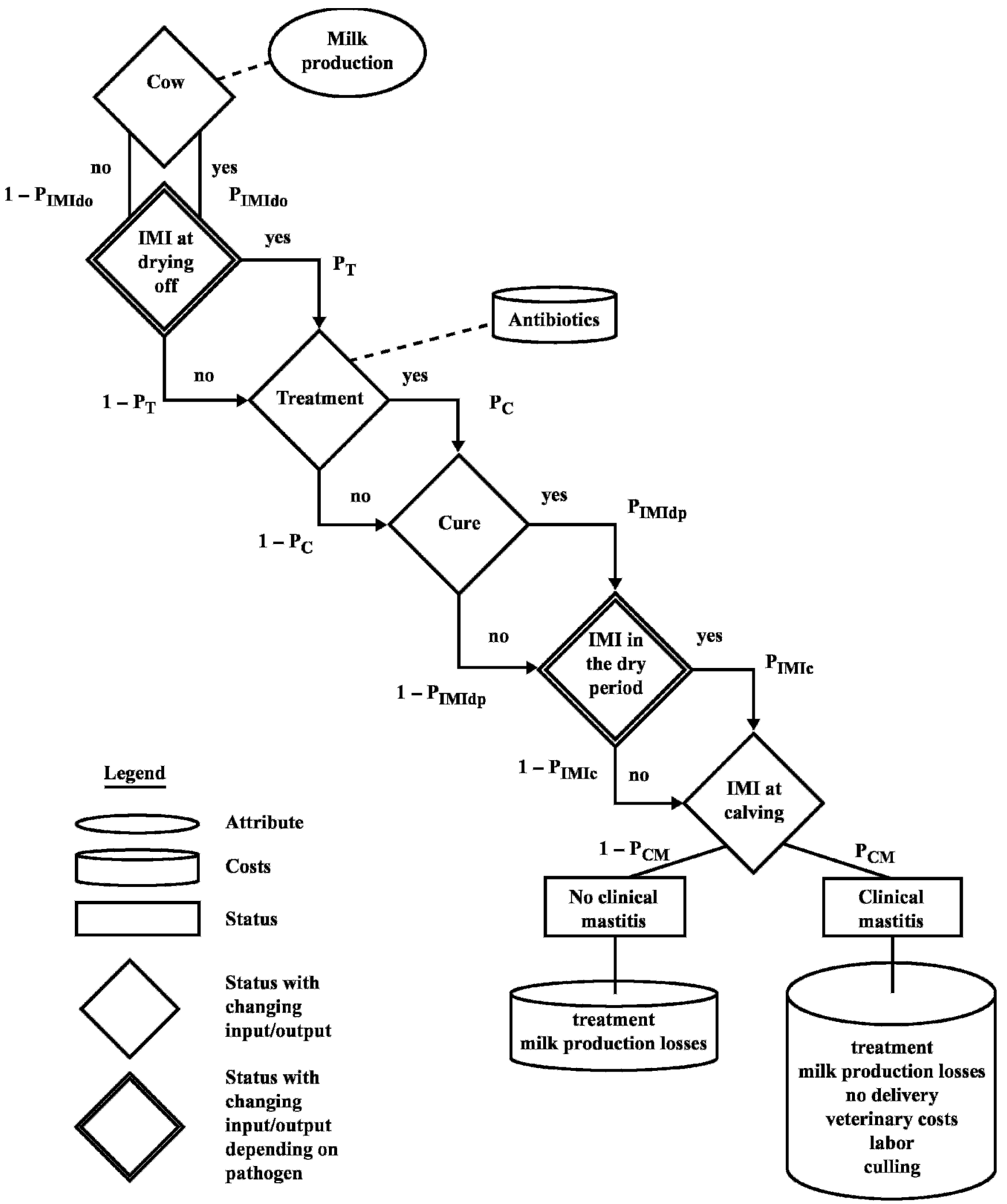

Figure 1. Schematic view of one process of the model, where $\mathrm{P}_{\mathrm{IMIdo}}=$ probability of infection at drying off; $\mathrm{P}_{\mathrm{T}}=$ probability of treatment; $\mathrm{P}_{\mathrm{C}}=$ probability of cure; $\mathrm{P}_{\mathrm{CT}}=$ probability of cure after treatment; $\mathrm{P}_{\mathrm{IMIc}}=$ probability of an infection at calving; $\mathrm{P}_{\mathrm{CM}}=$ probability of clinical mastitis after calving and; $\mathrm{P}_{\text {IMIdp }}=$ probability of infection during dry period. 
$\mathrm{CM}_{\mathrm{i}}$ can be 0 (no clinical mastitis) or 1 (clinical mastitis) and is dependent on the pathogen involved:

$$
\begin{aligned}
& \text { If } \operatorname{IMIc}_{\mathrm{i}}=\mathrm{NEG} \text { then } \mathrm{CM}_{\mathrm{i}}=0 \\
& \text { If } \mathrm{IMIc}_{\mathrm{i}} \neq \mathrm{NEG} \text { then } \mathrm{CM}_{\mathrm{i}}= \\
& \text { discrete }\left[(0,1) ;\left(\mathrm{P}_{\mathrm{CM}}, 1-\mathrm{P}_{\mathrm{CM}}\right)\right]
\end{aligned}
$$

Calculation of Costs. Costs of CMDP are caused by production losses, culling, veterinarian visits, antibiotics, discarded milk, labor, and costs of clinical mastitis. The costs are calculated per cow based on the dynamics of infection.

Costs of treatment of a cow (i) $\left(\mathrm{CT}_{\mathrm{i}}\right)$ consist of costs for treatment at drying off and costs of treatment of clinical cases:

$$
\mathrm{CT}_{\mathrm{i}}=\text { Cant, do } \times \mathrm{T}_{\mathrm{i}}+\text { Cant, } \mathrm{cm} \times \mathrm{CM}_{\mathrm{i}}
$$

where Cant,do are the costs of antibiotics for drying off and Cant,cm are the costs of antibiotics for treating a clinical mastitis case.

Costs of labor for each cow (i) $\left(\mathrm{CL}_{\mathrm{i}}\right)$ consist of costs of labor for drying off and costs of labor for treatment of clinical cases:

$$
\mathrm{CL}_{\mathrm{i}}=\mathrm{Tt}, \mathrm{do} \times \mathrm{Hr} \times \mathrm{T}_{\mathrm{i}}+\mathrm{Tt}, \mathrm{cm} \times \mathrm{Hr} \times \mathrm{CM}_{\mathrm{i}}
$$

where $\mathrm{Tt}$,do is the treatment time for drying off, $\mathrm{Hr}$ is the hourly rate of the farmer, and $\mathrm{Tt}, \mathrm{cm}$ is the treatment time for a clinical case.

Costs of production losses for cow (i) $\left(\mathrm{CP}_{\mathrm{i}}\right)$ :

$$
\begin{gathered}
\mathrm{CP}_{\mathrm{i}}=\mathrm{MP}_{\mathrm{i}} \times \mathrm{P}_{\mathrm{i}} \times \mathrm{Mpc} \times \mathrm{IMIc}_{\mathrm{i}}+\mathrm{Mp}_{\mathrm{i}} \times \mathrm{Pc}_{\mathrm{i}} \\
\times \mathrm{CMp} \times \mathrm{CM}_{\mathrm{i}}
\end{gathered}
$$

where $M P_{i}$ is the 305-d milk production of cow i, $P_{i}$ is the percentage of production losses of cow $i$ in the presence of an IMIc $\mathrm{c}_{\mathrm{i}}, \mathrm{Mpc}$ is the price of milk losses, and $\mathrm{Pc}_{\mathrm{i}}$ is the percentage of production losses caused by a case of clinical mastitis.

Culling costs $\left(\mathrm{CCul}_{\mathrm{i}}\right)$, veterinarian costs $\left(\mathrm{CVet}_{\mathrm{i}}\right)$, and costs of discarded milk $\left(\mathrm{Cd}_{\mathrm{i}}\right)$ for cow (i) occur when there is a case of clinical mastitis:

$$
\begin{gathered}
\mathrm{CCul}_{\mathrm{i}}=\mathrm{Ccul} \times \mathrm{CM}_{\mathrm{i}} \\
\mathrm{CVet}_{\mathrm{i}}=\mathrm{Cvet} \times \mathrm{CM}_{\mathrm{i}} \\
\mathrm{Cd}_{\mathrm{i}}=\mathrm{MP}_{\mathrm{i}} / 305 \times \mathrm{Td} \times \mathrm{Mpc} \times \mathrm{CM}_{\mathrm{i}}
\end{gathered}
$$

where Ccul are the culling costs, Cvet are the veterinarian costs, and $\mathrm{Td}$ are the days of antibiotic treatment.
After the individual cow processes are simulated, they are cumulated to herd-level outcomes. The total costs of IMI (C) around the dry period are:

$$
\begin{aligned}
\mathrm{C}=\sum_{\mathrm{i}=1}^{\mathrm{n}} \mathrm{CT}_{\mathrm{i}} & +\sum_{\mathrm{i}=1}^{\mathrm{n}} \mathrm{CL}_{\mathrm{i}}+\sum_{\mathrm{i}=1}^{\mathrm{n}} \mathrm{CP}_{\mathrm{i}}+\sum_{\mathrm{i}=1}^{\mathrm{n}} \mathrm{CCul}_{\mathrm{i}} \\
& +\sum_{\mathrm{i}=1}^{\mathrm{n}} \mathrm{CVet}_{\mathrm{i}}+\sum_{\mathrm{i}=1}^{\mathrm{n}} \mathrm{Cd}_{\mathrm{i}}
\end{aligned}
$$

where $\mathrm{n}$ is the number of cows.

Dry Cow Treatment. In this research 3 different DCT strategies were analyzed: blanket DCT, selective DCT, and no DCT. The difference between them is the probability of treatment. The probability of treatment was 1 for blanket treatment and 0 for no treatment. For selective DCT, the probability of treatment depended on the sensitivity and specificity of the selection procedure: With a high sensitivity of selection, infected cows are more likely to be treated; with a high specificity, uninfected cows are less likely to be treated. During the simulation of each treatment strategy, the model was updated until it reached a steady state defined as the convergence percentage. The convergence helps evaluate the stability of the output distributions during a simulation. Monitoring convergence was done by calculating the percentiles (0 to $100 \%$ in 5\% increments), mean, and standard deviation on the data generated for each output parameter at regular intervals throughout the simulation. These statistics were then compared with the same statistics calculated at the prior interval during the simulation. The amount of change in statistics due to the additional iterations was then calculated. When the convergence percentage reached $1.5 \%$, the model was ended.

Input Data. The economic input data seen in Table 1 are based on the literature and expert opinions for Dutch conditions. The input data in Table 2 for modeling the dynamics of infection were based on the literature and expertise. These data include the values for the probabilities necessary to simulate the dynamics of IMI around the dry period $\left(\mathrm{P}_{\text {IMIdo }}, \mathrm{P}_{\mathrm{T}}, \mathrm{P}_{\mathrm{C}}, \mathrm{P}_{\text {IMIdp }}, \mathrm{P}_{\text {IMIc }}\right.$, $\mathrm{P}_{\mathrm{CM}}$ ) and the combined results of the most likely (minimum, maximum) value of the input probabilities.

Because some of the probabilities needed were unavailable in the literature, experts were interviewed. Values from the literature were given a weight of 4 times an expert value because the literature is based on well-balanced experiments and is thus more reliable than expert opinions. When an average, a minimum, and a maximum were given in the literature, the data were put into a triangular distribution; when only a range was included, data were put into a uniform distribution; and if only an average was calculated, it was 
Table 1. Input values for economic parameters with their abbreviations and source

\begin{tabular}{llcl}
\hline Parameter & Abbreviation & Value $^{1}$ & Source \\
\hline Number of cows & $\mathrm{n}$ & 65 & NRS (www.nrs.nl) \\
Mean milk production, kg/yr & $\mathrm{MP}$ & 8,500 & NRS (www.nrs.nl) \\
Variance in milk production, kg/yr & - & 425 & NRS (www.nrs.nl) \\
Production losses with IMI at calving, \% & $\mathrm{P}$ & 2.5 & DeVos and Dijkhuizen (1998) \\
Production losses to clinical mastitis, \% & $\mathrm{Pc}$ & 5 & DeVos and Dijkhuizen (1998) \\
Price antibiotics, €/4 injectors & CAnt,do & $9.50(5,15)$ & Experts \\
Price antibiotics clinical case & $\mathrm{CAnt}, \mathrm{cm}$ & $40.00(30,50)$ & Experts \\
Costs of milk production losses, $€ / \mathrm{kg}$ & $\mathrm{Mpc}$ & $0.12(0.08,0.16)$ & H. Hogeveen (unpublished data) \\
Hourly rate, $€$ & $\mathrm{Hr}$ & $18(10,30)$ & Farm \\
Time per treatment, min & $\mathrm{Tt}, \mathrm{do}$ & 2 & Experts \\
Time treatment clinical case, h & $\mathrm{Tt}, \mathrm{cm}$ & 2 & Experts \\
Culling costs, $€$ & $\mathrm{Ccul}$ & $600(400,800)$ & Van der Walle (2004) using method of Houben et al. (1994) \\
Veterinarian costs/consult, $€$ & $\mathrm{Cvet}$ & $30(15,45)$ & - \\
Veterinarian help, \% & - & 0.25 & Experts \\
Days of milk withdrawal & $\mathrm{Td}$ & 5 & Experts \\
Probability of culling, \% & - & 0.12 & - \\
\hline
\end{tabular}

${ }^{1}$ Values in parentheses are cheap and expensive options.

used as a fixed value. The experts had to be familiar with Dutch dairy practices and with the knowledge and research carried out on mastitis in the dry period. Ten experts were approached and all agreed to cooperate in the research. The experts were asked to fill in a matrix with minimum, maximum, and most likely probabilities for the different pathogens per aspect included in the model. Because not every expert could fill in a minimum, most likely, and maximum value, the expert data were put into a triangular distribution when 3 values were known, a uniform distribution when 2 val- ues were known, and a fixed value when only 1 value was known, as with the values derived from the literature. By stochastic simulation, these distributions from the literature and expertise were combined to estimate a most likely value for the different probabilities in the default calculation.

Sensitivity Analysis. First, a sensitivity analysis identified the probabilities with the largest relative changes for CMDP for blanket, selective, and no DCT. All input probabilities with values between -20 and $20 \%$ of the default value were tested. The 10 probabili-

Table 2. Most likely input probabilities (with minimum and maximum input probability in parentheses) for the dynamics of infection ${ }^{1}$ based on the literature ${ }^{2}$ and expertise

\begin{tabular}{lcccccc}
\hline & \multicolumn{5}{c}{ Infection parameter } \\
\cline { 2 - 6 } Pathogen $^{3}$ & $\mathrm{P}_{\text {IMIdo }}(15 \%)$ & $\mathrm{P}_{\mathrm{T}}{ }^{4}$ & $\mathrm{P}_{\mathrm{CS}}$ & $\mathrm{P}_{\mathrm{CT}}$ & $\mathrm{P}_{\text {IMIc }}(10 \%)$ & $\mathrm{P}_{\mathrm{CM}}$ \\
\hline \multirow{2}{*}{$\mathrm{SAG}$} & 0.02 & $0.78^{5}$ & 0.2 & 0.93 & 0.25 & 0.27 \\
& $(0,0.5)$ & $(0.6,0.85)$ & $(0.03,0.45)$ & $(0.75,1)$ & $(0.09,0.65)$ & $(0.08,0.58)$ \\
SDY & 0.03 & $0.78^{5}$ & $0.22^{5}$ & 0.83 & 0.19 & 0.20 \\
& $(0,0.15)$ & $(0.6,0.85)$ & $(0.18,0.30)$ & $(0.7,1)$ & $(0,0.65)$ & $(0.01,0.58)$ \\
SUB & 0.10 & $0.78^{5}$ & $0.22^{5}$ & 0.81 & 0.23 & 0.36 \\
& $(0.05,0.16)$ & $(0.6,0.85)$ & $(0.15,0.30)$ & $(0.5,1)$ & $(0.05,0.65)$ & $(0.04,0.74)$ \\
SAU & 0.07 & $0.78^{5}$ & 0.19 & 0.71 & 0.17 & 0.36 \\
& $(0.03,0.15)$ & $(0.6,0.85)$ & $(0.01,0.45)$ & $(0.3,1)$ & $(0.11,0.35)$ & $(0.08,0.58)$ \\
ECO & 0.10 & $0.78^{5}$ & 0.6 & 0.8 & 0.19 & 0.14 \\
& $(0.01,0.15)$ & $(0.6,0.85)$ & $(0.02,1)$ & $(0.25,1)$ & $(0.04,0.95)$ & $(0.05,0.58)$ \\
\hline
\end{tabular}

${ }^{1} \mathrm{P}_{\text {IMIdo }}=$ probability of infection at drying off; $\mathrm{P}_{\mathrm{T}}=$ probability of treatment; $\mathrm{P}_{\mathrm{CS}}=$ probability of spontaneous cure; $\mathrm{P}_{\mathrm{CT}}=$ probability of cure after treatment; $\mathrm{P}_{\mathrm{IMIc}}=$ probability of an infection at calving; and $\mathrm{P}_{\mathrm{CM}}=$ probability of clinical mastitis after calving.

${ }^{2}$ Østerås et al., 1991; Schukken et al., 1993; Hogan et al., 1994, 1995; Østerås et al., 1994; Berry et al., 1997; Bradley and Green, 2001; Berry and Hillerton, 2002b; Dingwell et al., 2002; Huxley et al., 2002; Godden et al., 2003; Robert et al., 2006.

${ }^{3} \mathrm{SAG}=$ Streptococcus agalactiae, $\mathrm{SDY}=$ Streptococcus dysgalactiae, $\mathrm{SUB}=$ Streptococcus uberis, $\mathrm{SAU}=$ Staphylococcus aureus, and ECO = Escherichia coli.

${ }^{4}$ For blanket dry cow therapy (DCT), all pathogens have the value 1 and for no DCT, all pathogens have the value 0 .

${ }^{5}$ Value is based only on expertise because no specific literature that can be used for Dutch circumstances is available. 
Table 3. Results of default calculation for blanket, selective, and no dry cow therapy (5\%, 95\% percentiles in parentheses)

\begin{tabular}{lccc}
\hline Item & Blanket & Selective & No \\
\hline IMIdo, ${ }^{1} \%$ & $14.98(7.69,23.08)$ & $14.97(7.69,23.08)$ & $14.97(7.69,23.08)$ \\
Treatment, \% & 100 & $35(23,46)$ & 0 \\
IMI at calving & $7.48(3.08,12.31)$ & $12.33(6.15,20)$ & $19.28(12.31,27.69)$ \\
Clinical mastitis, \% & $1.77(0,4.62)$ & $3.17(0,7.69)$ & $5.13(1.54,10.77)$ \\
Treatment costs, €/cow & $10.10(10.10,10.10)$ & $3.50(2.33,4.66)$ & 0 \\
Production losses, €/cow & $1.27(0.50,2.15)$ & $2.10(1.03,3.35)$ & $3.28(2.03,4.71)$ \\
Clinical mastitis, €/cow & $4.23(0,14.62)$ & $8.13(0,22.93)$ & $14.74(1.99,38.50)$ \\
Total costs, $€ / c o w$ & $15.60(10.61,26.61)$ & $13.72(4.86,29.41)$ & $18.02(4.08,42.60)$ \\
\hline
\end{tabular}

${ }^{1}$ IMIdo = infection at drying off.

ties with the largest relative effect on the results were examined in detail. As a next step, the economic parameters were tested with realistic variation. These values are given in Table 1 . The probabilities with respect to the dynamics of infection were tested with the 5 and 95\% values given by the literature and experts.

Scenarios. Specific antibiotic use at drying off was tested to determine the economic consequences of different possibilities. First, we assumed that with an expensive antibiotic ( $€ 13)$, the probability of cure after treatment would increase by $10 \%$, and with a cheap antibiotic (€6), the probability of cure after treatment would decrease by $10 \%$. This was combined with a high $(95 \%$ value by experts) and low (5\% value by experts) infection rate (IMIdp). The scenarios tested were low infection rate and cheap antibiotic, low infection rate and expensive antibiotic, high infection rate and cheap antibiotic, high infection rate and expensive antibiotic, normal infection rate and cheap antibiotic, and normal infection rate and expensive antibiotic.

Our second scenario analysis assumed the price of the antibiotic was the same, and considered specific antibiotic use and sensitivity of selection of cows for selective treatment. This analysis was done for 6 situations, A (selective DCT, specific antibiotic use, and good selection), B (selective DCT, specific antibiotic use, and bad selection), C (selective DCT, general antibiotics, and good selection), D (selective DCT, general antibiotics, and bad selection), E (blanket DCT and specific antibiotic use), and F (blanket DCT and general antibiotic use).

\section{RESULTS}

\section{Default}

For the default calculation, the most likely probabilities from input values are used. In Table 2, the most likely, minimum, and maximum values of these probabilities are shown. For all input probabilities, variation is shown. The major variation occurs in the probabilities of having clinical mastitis after calving, having an infec- tion at calving, and having an IMI at the moment of drying off. According to the values, the dynamics of IMI during the dry period do differ between pathogens. The probability with the largest difference between pathogens is the probability of a spontaneous cure (Pcs), for which SAU is given by a probability of 0.19 and ECO by a probability of 0.6 .

All costs are calculated per cow per lactation. The variation in CMDP within each treatment strategy is large. The variation for selective and no DCT is larger than for blanket DCT. When using the default values, selective DCT has the lowest average CMDP of $€ 13.72$ ( $€ 4.86$ to $€ 29.41$ ), followed by blanket DCT with CMDP of $€ 15.60$ ( $€ 10.61$ to $€ 26.61$ ) and no DCT with CMDP of $€ 18.02$ ( $€ 4.08$ to $€ 42.60$ ). As shown in Table 3, treatment has a positive effect on the dynamics of IMI around the dry period because of a lower percentage of infections at calving and a lower percentage of cows getting clinical mastitis.

\section{Sensitivity Analysis}

The most important factors resulting from the first sensitivity analysis are CM; Cant,do; Hr; Cmp; Ccul; $\mathrm{P}_{\mathrm{i}}$; Cant,cm; IMIdp; Pc; and IMIdo. The results of the sensitivity analysis for the 10 most important probabilities for blanket, selective, and no DCT, using realistic variation, are shown in Figure 2. The economic parameter with the largest influence on the mastitis costs around the dry period per cow is the cost of antibiotics. Moreover, the cost of milk losses and the hourly rate for labor of the farmer have a large influence. The probabilities of the dynamics of infection with the most influence on the costs are clinical mastitis, probability of culling, and IMIdp.

\section{Scenarios}

The results of the first scenario analysis are shown in Table 4. Overall, when looking at the average costs, only small differences between treatment strategies occurred. The average costs of blanket and selective DCT 


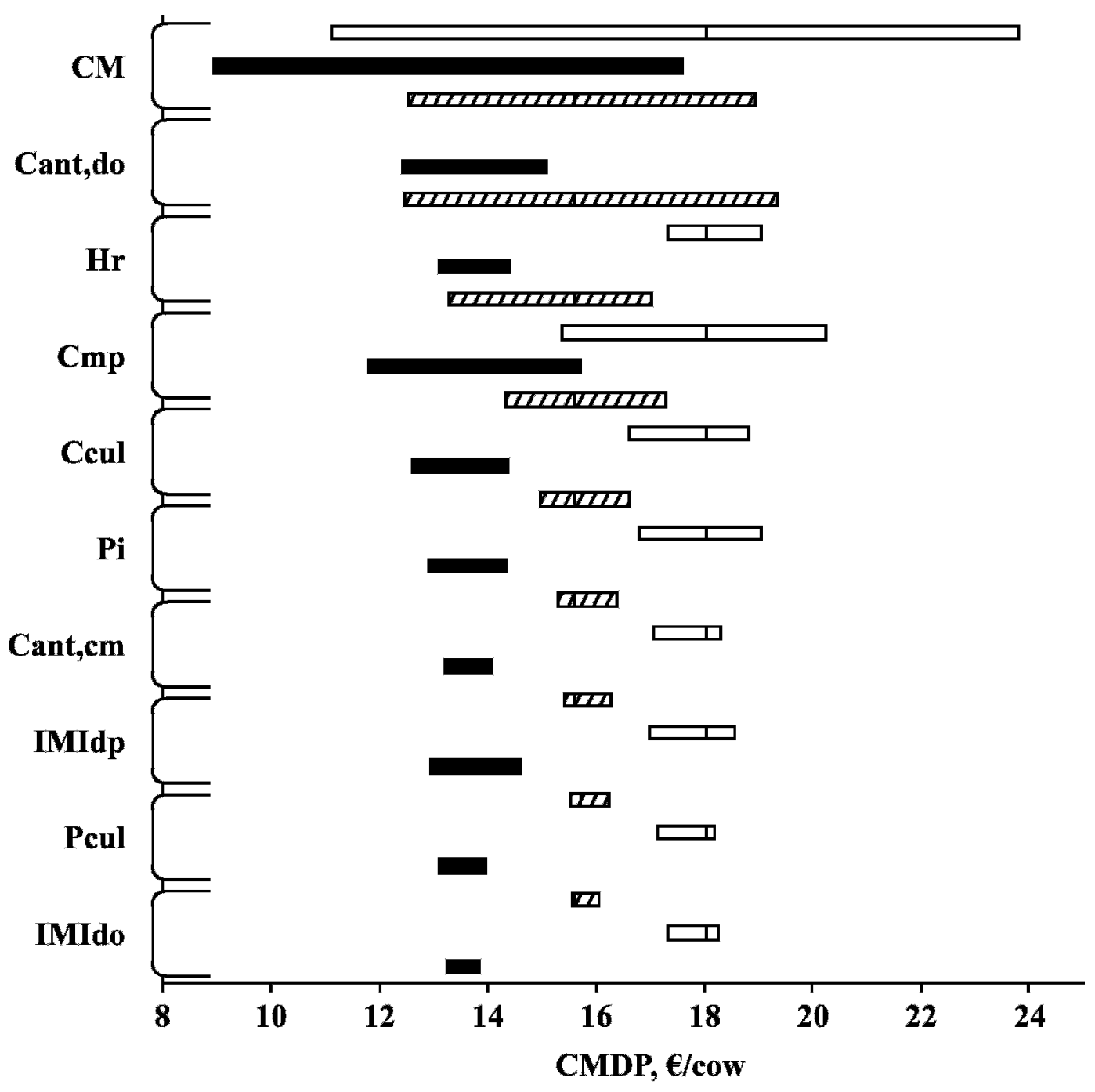

Figure 2. Results of the sensitivity analysis for the most important factors in cost of mastitis around the dry period (CMDP): probability of clinical mastitis (CM), costs of antibiotics at drying off (Cant,do), hourly rate of the farmer (Hr), cost of milk production losses (Cmp), cost of culling (Ccul), percentage of production losses per cow ( $\mathrm{Pi})$, costs of antibiotics to treat clinical cases $(\mathrm{Cant}$,cm), probability of new infections during the dry period (IMIdp), probability of culling (Pcul), and probability of infection at drying off (IMIdo) for blanket (diagonal hatch), selective (black), and no dry cow therapy (white) when the probabilities regarding the dynamics of infection are varied between $5 \%$ (left side of the bar) and 95\% (right side of the bar) of the expert values and the economic parameters are varied with fixed values. The line in the middle of the bars shows the default CMDP.

are close together, but as the price of antibiotics increases, the differences are larger. In every scenario the variation of blanket DCT is smallest, followed by selective DCT, and then by no DCT. In the scenario with a low infection rate and low costs of antibiotics, no DCT is economically better, but variation is then highest as well.

The results from the second scenario analysis are shown in Figure 3. From Figure 3 it becomes clear that a good selection of the animals that will be treated is important. The scenarios with a bad selection (10\% less sensitivity) have higher average costs and more varia- tion [ $€ 15.54$ ( $€ 5.24$ to $€ 33.81$ ) and $€ 14.27$ ( $€ 5.08$ to $€ 31.78)]$ than the scenarios with a good selection [€11.83 (€4.59 to €27.11) and €13.02 (€4.81 to €29.05)]. The selection is more important than specific antibiotic use.

\section{DISCUSSION}

There was little variation in the average costs of the different treatment strategies. The difference between the DCT strategies was due to the variation in CMDP. The variation in costs was the lowest when using blan- 
Table 4. Most likely costs (€) of IMI around the dry period (5\%, 95\% percentiles in parentheses) for high $(+5 \%)$, mean, and low $(-5 \%)$ values of infection rate and high (€13), mean (€9.50), and low (€6) prices of antibiotics when assuming that an expensive antibiotic has a better cure after treatment of $10 \%$ and a cheap antibiotic has a cure after treatment of $10 \%$ less

\begin{tabular}{|c|c|c|c|c|}
\hline \multirow{2}{*}{$\begin{array}{l}\text { Dry cow } \\
\text { therapy }\end{array}$} & \multirow{2}{*}{$\begin{array}{c}\text { Price of } \\
\text { antibiotics }\end{array}$} & \multicolumn{3}{|c|}{ Infection rate } \\
\hline & & Low & Most likely & High \\
\hline \multirow[t]{5}{*}{ Blanket } & Low & $\begin{array}{l}18.10 \\
(8.46,35.90)\end{array}$ & $\begin{array}{l}16.86 \\
(8.20,32.24)\end{array}$ & $\begin{array}{l}23.02 \\
(10.46,43.47)\end{array}$ \\
\hline & Mean & 14.49 & 15.60 & 16.56 \\
\hline & & $(10.37,25.23)$ & $(10.61,26.61)$ & $(10.85,29.43)$ \\
\hline & High & 16.68 & 17.40 & 17.98 \\
\hline & & $(13.85,25.94)$ & $(13.86,26.92)$ & $(14.10,29.07)$ \\
\hline \multirow[t]{5}{*}{ Selective } & Low & $\begin{array}{l}14.76 \\
(4.80,32.73)\end{array}$ & $\begin{array}{l}15.68 \\
(4.82,34.96)\end{array}$ & $\begin{array}{l}20.34 \\
(6.51,43.61)\end{array}$ \\
\hline & Mean & 12.12 & 13.72 & 15.45 \\
\hline & & $(4.28,27.09)$ & $(4.86,29.41)$ & $(5.56,32.93)$ \\
\hline & High & 12.93 & 13.86 & 15.46 \\
\hline & & $(5,25.92)$ & $(5.82,29.50)$ & $(6.59,31.24)$ \\
\hline \multirow[t]{6}{*}{ No } & Low & 14.43 & 17.98 & 21.28 \\
\hline & & $(2.90,34.70)$ & $(4.15,40.04)$ & $(5.06,46.25)$ \\
\hline & Mean & 14.65 & 18.02 & 22.06 \\
\hline & & $(2.83,35.26)$ & $(4.08,42.60)$ & $(5.43,49.04)$ \\
\hline & High & 14.40 & 18.06 & 22.06 \\
\hline & & $(2.64,34.98)$ & $(4.19,40.93)$ & $(5.30,48.03)$ \\
\hline
\end{tabular}

ket DCT, followed by selective DCT and no DCT. The treatment strategy to be chosen is therefore very dependent on the risk attitude of the farmer and farm management conditions. A farmer willing to take more risks and wanting the lowest DCT costs will, at base conditions, choose selective DCT. In that situation the farmer risks having high costs. The average costs of blanket DCT are higher than the average costs for selective DCT, but a farmer who does not want to take risks will choose selective DCT because the variation is smaller.
The costs of different treatment strategies are strongly influenced by the economic input values of the model, which in this case are based on current Dutch standards. Most economic variables cannot be influenced by the farmer, may vary between countries, and depend on specific circumstances. The cost of milk production losses, for example, depends on the presence of a quota system. With a quota, the costs of milk production losses will be lower. With a quota, the production potential of a farm is the quota, and a farmer will pro-

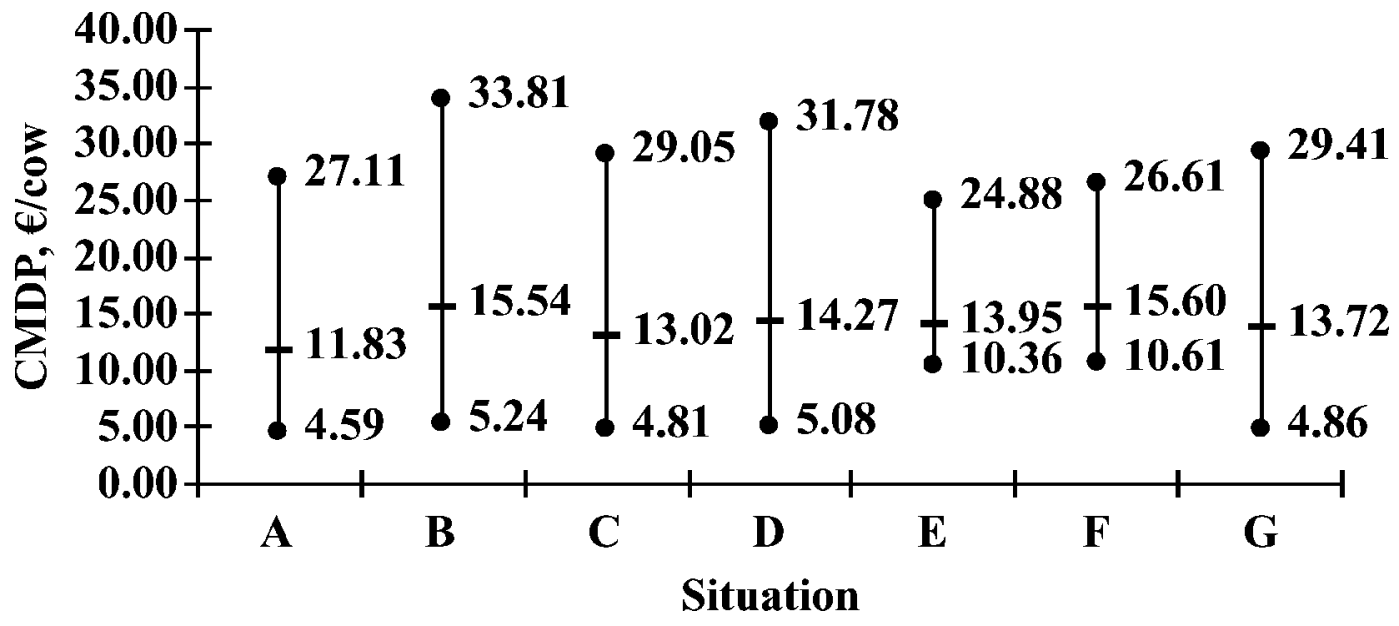

Figure 3. The costs of mastitis around the dry period (CMDP) for specific antibiotic use and good or bad selection of the cows for dry cow therapy (DCT) in different situations: A = selective DCT, specific antibiotic use, and good selection; B = selective DCT, specific antibiotic use, and bad selection; C = selective DCT, general antibiotics, and good selection; D = selective DCT, general antibiotics, and bad selection; $\mathrm{E}=$ blanket DCT and specific antibiotic use; F = blanket DCT and general antibiotic use; and $\mathrm{G}=$ selective DCT, general antibiotics, and default selection. 
duce milk to fill the quota. The costs of milk production losses are then the costs of keeping an extra cow (extra feed, manure, etc.). These costs are, in general, lower than the milk price. Without a quota, the production capacity is the number of cows and cost is approximately the lower milk production times the milk price.

In contrast to economic factors, many infection dynamic factors can be influenced by the farmer. The values of IMIdo and IMIdp are farm specific, dependent on management strategies (Dingwell et al., 2003; McDougall, 2003; Green et al., 2005), and influence the decision about DCT strategy. A low IMIdo means, in general, good mastitis management. A low IMIdp means, in general, good hygiene during the dry period. In this model, management as such is not considered, although by changing IMIdo and IMIdp, management can be accounted for. Further research should include management factors in this way.

Because not all probabilities needed for the model could be found in the literature, expert opinions were used with the known literature. These are necessarily subjective estimations and biases can occur. It is unclear which heuristics an expert uses when attempting to provide estimates. Likely biases include availability, their ability to be representative, adjustment and anchoring, lack of precise knowledge, culture of the organization, conflicting agendas, unwillingness to consider extremes, eagerness to say the right thing, units used in the estimation, lack of time, and the assumption that the expert is right (Vose, 2000). Because literature is more reliable, whenever possible we included these values as a value with 4 times more weight than the expert values. However, for most variables, the expert opinions deviated only slightly from information from the literature. The expert probabilities for spontaneous cure, ranging from 0.1 for Staph. aureus to 0.78 for E. coli, were in consensus with the literature. In the literature, probabilities were found between 0.25 and 0.38 (Østerås et al., 1991, 1994; Berry et al., 1997) without distinguishing between types of pathogens. The expert values for probability of cure after treatment, ranging from 0.40 to 0.88 , were in line with the literature, in which values were found between 0.63 and 0.83 (Østerås et al., 1994; Berry et al., 1997; Huxley et al., 2002), without distinguishing between types of pathogens.

The main exception was in values for IMIdp, which were higher in this study than those found in the literature: 0.20 (Østerås et al., 1994) and 0.29 (Berry and Hillerton, 2002b). Moreover, probabilities of clinical mastitis after calving were in line (0.26 to 0.29$)$ with the literature: 0.21 to 0.29 (Bradley and Green, 2001). But clinical cases, which occur during the dry period and are cured during the same dry period, are not in- cluded. This causes a small underestimation of the costs for clinical cases. It should be noted that in this study no difference was made in the costs of clinical mastitis caused by different pathogens. The CMDP are underestimated because the cost associated with spread of infections after calving from infected cows is not included.

In this research, the use of a teat seal (Berry and Hillerton, 2002a; Huxley et al., 2002; Godden et al., 2003) as therapy was not included because in the Netherlands the use of a teat seal is rare. The model can be adjusted for the use of a teat seal when different probabilities about the dynamics of infection are known.

Labor costs were difficult to quantify. Some farmers think of labor as a very important measure, whereas other farmers do not. For most Dutch family farms, the opportunity costs of labor are zero. Because of irritation caused by mastitis, the utility a farmer attaches to labor is high. For $24 \%$ of the Dutch farmers, the extra labor needed is the most disturbing aspect of mastitis (Kuiper et al., 2005). By valuing labor, this disturbance was taken into account as costs.

Because the optimal DCT decision depends on the values of probabilities such as IMIdp, IMIc, and Cant,do, farmers need a farm-specific calculation of the CMDP. This can help them choose the best DCT strategy for their farms. With the stochastic Monte Carlo simulation model developed here, it is possible to identify the optimal situation for each specific farm.

\section{CONCLUSIONS}

A model to calculate the farm-specific costs of mastitis around the dry period was built using literature and expertise. The expertise resembled known data from the literature, except for IMIdp, for which the expert opinions gave a relatively high value, and $\mathrm{CM}$, for which they gave a low value. With the default values of the input variables and probabilities, selective DCT is economically the best option, although the differences are small. The sensitivity analysis showed that the rate of infection (especially IMIdp and CM) and the costs of antibiotics have a large influence on the results. With a small change in these probabilities, the economically optimal decision will move toward blanket DCT. Because the optimal decision depends on these and other measures that vary widely between farms, it is necessary to be able to make a farm-specific calculation of the costs of IMI around the dry period.

\section{ACKNOWLEDGMENTS}

We would like to thank the experts who participated in the research because without them no realistic input 
parameters and probabilities would be available. We would like to thank Rinse Jan Boersma from Intervet for the discussion that initiated this research and Linda $\mathrm{McPhee}$ for the technical writing assistance.

\section{REFERENCES}

Berry, E. A., and J. E. Hillerton. 2002a. The effect of an intramammary teat seal on new intramammary infections. J. Dairy Sci. 85:2512-2520.

Berry, E. A., and J. E. Hillerton. 2002b. The effect of selective dry cow treatment on new intramammary infections. J. Dairy Sci. 85:112-121.

Berry, S. L., J. Maas, J. H. Kirk, J. P. Reynolds, I. A. Gardner, and A. Ahmadi. 1997. Effects of antimicrobial treatment at the end of lactation on milk yield, somatic cell count, and incidence of clinical mastitis during the subsequent lactation in a dairy herd with a low prevalence of contagious mastitis. J. Am. Vet. Med. Assoc. 211:207-211.

Bradley, A. J., and M. J. Green. 2000. A study of the incidence and significance of intramammary enterobacterial infections acquired during the dry period. J. Dairy Sci. 83:1957-1965.

Bradley, A. J., and M. J. Green. 2001. An investigation of the impact of intramammary antibiotic dry cow therapy on clinical coliform mastitis. J. Dairy Sci. 84:1632-1639.

DeVos, C. J., and A. A. Dijkhuizen. 1998. Economic aspects of mastitis and mastitis prevention. Internal Report. Department of Animal Health Economics, Wageningen University, the Netherlands. [in Dutch]

Dingwell, R. T., T. F. Duffield, K. E. Leslie, G. P. Keefe, L. DesCoteaux, D. F. Kelton, K. D. Lissemore, Y. H. Schukken, P. Dick, and R. Bagg. 2002. The efficacy of intramammary tilmicosin at dryingoff, and other risk factors for the prevention of new intramammary infections during the dry period. J. Dairy Sci. 85:3250-3259.

Dingwell, R. T., D. F. Kelton, and K. E. Leslie. 2003. Management of the dry cow in control of peripartum disease and mastitis. Vet. Clin. North Am. Food Anim. Pract. 19:235-265.

Dodd, F. H., D. R. Westgarth, F. K. Neave, and R. G. Kingwell. 1969. Mastitis-The strategy of control. J. Dairy Sci. 52:689-695.

Godden, S., P. Rapnicki, S. Stewart, J. Fetrow, A. Johnson, R. Bey, and R. Farnsworth. 2003. Effectiveness of an internal teat seal in prevention of new intramammary infections during the dry and early-lactation periods in dairy cows when used with a dry cow intramammary antibiotic. J. Dairy Sci. 86:3899-3911.

Green, M. J., L. E. Green, A. J. Bradley, P. R. Burton, Y. H. Schukken, and G. F. Medley. 2005. Prevalence and associations between bacterial isolates from dry mammary glands of dairy cows. Vet. Rec. 156:71-77.

Hogan, J. S., K. L. Smith, D. A. Todhunter, and P. S. Schoenberger. 1994. Efficacy of dry cow therapy and a Propionibacterium acnes product in herds with low somatic cell count. J. Dairy Sci. 77:3331-3337.

Hogan, J. S., K. L. Smith, D. A. Todhunter, and P. S. Schoenberger. 1995. Efficacy of recombinant bovine interleukin-2 as an adjunct to dry cow therapy. J. Dairy Sci. 78:1062-1067.

Houben, E. H. P., A. A. Dijkhuizen, J. A. M. van Arendonk, and R. B. M. Huirne. 1993. Short- and long-term production losses and repeatability of clinical mastitis in dairy cattle. J. Dairy Sci. 76:2561-2578.

Houben, E. H. P., R. B. M. Huirne, A. A. Dijkhuizen, and A. R. Kristensen. 1994. Optimal replacement of mastitis cows determined by a hierarchic Markov process. J. Dairy Sci. 77:2975-2993.

Huxley, J. N., M. J. Green, L. E. Green, and A. J. Bradley. 2002. Evaluation of the efficacy of an internal teat sealer during the dry period. J. Dairy Sci. 85:551-561.

Kuiper, D., J. Jansen, R. J. Renes, C. Leeuwis, and H. van der Zwaag. 2005. Social factors related to mastitis control practices: The role of dairy farmers' knowledge, attitude, values, behaviour and networks. Pages 576-582 in Mastitis in Dairy Production: Current Knowledge and Future Solutions. Proc. 4th Int. Dairy Fed. Int. Mastitis Conf., Maastricht, the Netherlands. Wageningen Academic Publishers, Wageningen, the Netherlands.

McDougall, S. 2003. Management factors associated with the incidence of clinical mastitis over the non-lactation period and bulk tank somatic cell count during the subsequent lactation. N.Z. Vet. J. 51:63-72.

McNab, W. B., and A. H. Meek. 1991. A benefit cost analysis of dry-cow mastitis therapy in dairy cattle in Ontario. Can. Vet. J. $32: 347-353$

Østerås, O. 2000. The costs of mastitis-An opportunity to gain more money. Page 67-77 in Proc. British Mastitis Conf. Institute for Animal Health. Milk Development Council, Shepton Mallet, UK.

Østerås, O., J. Aursjo, G. G. Gjul, and A. Jorstad. 1994. Effect of drycow therapy on subclinical mastitis-An evaluation of long-acting and short-acting intramammaria. J. Vet. Med. B 41:529-540.

Østerås, O., L. Sandvik, J. Aursjo, G. G. Gjul, and A. Jorstad. 1991. Assessment of strategy in selective dry cow therapy for mastitis control. J. Vet. Med. B 38:513-522.

Robert, A., H. Seegers, and N. Bareille. 2006. Incidence of intramammary infections during the dry period without or with antibiotic treatment in dairy cows-A quantitative analysis of published data. Vet. Res. 37:25-48.

Schukken, Y. H., J. Vanvliet, D. Vandegeer, and F. J. Grommers. 1993. A randomized blind trial on dry cow antibiotic infusion in a low somatic cell count herd. J. Dairy Sci. 76:2925-2930.

Van der Walle, K. 2004. Gebruikswaarde van melkvee. Internal report. Animal Sciences Group Wageningen UR, Lelystad, the Netherlands.

Vose, D. 2000. Defining distributions from expert opinion. Pages 262 271 in Risk Analysis: A Quantitative Guide. 2nd ed. John Wiley \& Sons, Chichester, UK. 